\title{
CARRY TRADE AND MOMENTUM IN CURRENCY MARKETS
}

\author{
Craig Burnside \\ Martin S. Eichenbaum \\ Sergio Rebelo \\ Working Paper 16942 \\ http://www.nber.org/papers/w16942
NATIONAL BUREAU OF ECONOMIC RESEARCH
1050 Massachusetts Avenue
Cambridge, MA 02138
April 2011

Burnside, C, Eichenbaum, M and Rebelo, S. 2011. Carry Trade and Momemtum in Currency Markets. Annu. Rev. Fin. Econ.: Submitted. Doi: 10.1146/annurev-financial-102710-144913 The views expressed herein are those of the authors and do not necessarily reflect the views of the National Bureau of Economic Research.

NBER working papers are circulated for discussion and comment purposes. They have not been peerreviewed or been subject to the review by the NBER Board of Directors that accompanies official NBER publications.

(C) 2011 by Craig Burnside, Martin S. Eichenbaum, and Sergio Rebelo. All rights reserved. Short sections of text, not to exceed two paragraphs, may be quoted without explicit permission provided that full credit, including $(\subset$ notice, is given to the source. 
Carry Trade and Momentum in Currency Markets

Craig Burnside, Martin S. Eichenbaum, and Sergio Rebelo

NBER Working Paper No. 16942

April 2011

JEL No. F31

\title{
ABSTRACT
}

We examine the empirical properties of the payoffs to two popular currency speculation strategies: the carry trade and momentum. We review three possible explanations for the apparent profitability of these strategies. The first is that speculators are being compensated for bearing risk. The second is that these strategies are vulnerable to rare disasters or peso problems. The third is that there is price pressure in currency markets.

\author{
Craig Burnside \\ Department of Economics \\ Duke University \\ 213 Social Sciences Building \\ Durham, NC 27708-0097 \\ and NBER \\ burnside@econ.duke.edu \\ Martin S. Eichenbaum \\ Department of Economics \\ Northwestern University \\ 2003 Sheridan Road \\ Evanston, IL 60208 \\ and NBER \\ eich@northwestern.edu
}

Sergio Rebelo

Northwestern University

Kellogg School of Management

Department of Finance

Leverone Hall

Evanston, IL 60208-2001

and NBER

s-rebelo@ northwestern.edu 


\section{Introduction}

In this survey we examine the empirical properties of the payoffs to two currency speculation strategies: the carry trade and momentum. We then assess the plausibility of the theories proposed in the literature to explain the profitability of these strategies.

The carry trade consists of borrowing low-interest-rate currencies and lending highinterest-rate currencies. The momentum strategy consists of going long (short) on currencies for which long positions have yielded positive (negative) returns in the recent past.

The carry trade, one of the oldest and most popular currency speculation strategies, is motivated by the failure of uncovered interest parity (UIP) documented by Bilson (1981) and Fama (1984). ${ }^{1}$ This strategy has received a great deal of attention in the academic literature as researchers struggle to explain its apparent profitability. Papers that study this strategy include Lustig \& Verdelhan (2007), Brunnermeier et al. (2009), Jordà \& Taylor (2009), Farhi et al. (2009), Lustig et al. (2009), Rafferty (2010), Burnside et al. (2011), and Menkhoff et al. (2011a).

In related work, a number of authors have studied the properties of currency momentum strategies. These authors include Okunev and White (2003), Lustig et al. (2009), Menkhoff et al. (2011a, 2011b), Moskowitz et al. (2010), Rafferty (2010), and Asness et al. (2009).

We begin by addressing the question: is the profitability of the carry trade and momentum strategies just compensation for risk, at least as conventionally measured? After reviewing the empirical evidence we conclude that the answer is no. This conclusion rests on the fact that the covariance between the payoffs to these two strategies and conventional risk factors is not statistically significant. ${ }^{2}$

The difficulty in explaining the profitability of the carry trade with conventional risk factors has led researchers such as Lustig et al. (2009) and Menkhoff et al. (2011a) to

\footnotetext{
${ }^{1}$ See Hodrick (1987) and Engel (1996) for surveys of the literature on uncovered interest parity.

${ }^{2}$ This finding is consistent with work documenting that one can reject consumption-based asset pricing models using data on forward exchange rates. See, e.g. Bekaert and Hodrick (1992) and Backus, Foresi, and Telmer (2001)).
} 
construct empirical risk factors specifically designed to price the average payoffs to portfolios of carry trade strategies. One natural question is whether these risk factors explain the profitability of the momentum strategy. We find that they do not.

An alternative explanation for the profitability of our two strategies is that it reflects the presence of rare disasters or peso problem explanations. We argue, on empirical grounds, that the 2008 financial crisis cannot be used as an example of the kind of rare disaster that rationalizes the profitability of currency trading. The reason is simple: momentum made money during the financial crisis.

We then consider the literature that uses currency options data to characterize the nature of the peso event that rationalizes the profitability of carry and momentum. Based on this analysis we argue that the peso event features moderate losses but a high value of the stochastic discount factor (SDF).

Finally, we explore an alternative explanation for the profitability of the carry trade and momentum strategies. This alternative relies on the existence of price pressure in foreign exchange markets. By price pressure we mean that the price at which investors can buy or sell currencies depends on the quantity they wish to transact. Price pressure introduces a wedge between marginal and average payoffs to a trading strategy. As a result, observed average payoffs can be positive even though the marginal trade is not profitable. So, traders do not increase their exposure to the strategy to the point where observed average risk-adjusted payoffs are zero.

The paper is organized as follows. In Section 2 we describe the empirical properties of the payoffs to the two currency strategies that we consider. In Section 3 we discuss riskbased explanations for the profitability of these strategies. Section 4 discusses the impact on inference that results from rare disasters or peso problems. Section 5 provides a brief discussion of the implications of price pressure. A final section concludes. 


\section{Currency strategies}

In this section we describe the carry trade and currency momentum strategies.

The carry trade strategy This strategy consists of borrowing low-interest-rate currencies and lending high-interest-rate currencies. Assume that the domestic currency is the U.S. dollar (USD) and denote the USD risk-free rate by $i_{t}$. Let the interest rate on risk-free foreign denominated securities be $i_{t}^{*}$. Abstracting from transactions costs, the payoff to taking a long position on foreign currency is:

$$
z_{t+1}^{L}=\left(1+i_{t}^{*}\right) \frac{S_{t+1}}{S_{t}}-\left(1+i_{t}\right) .
$$

Here $S_{t}$ denotes the spot exchange rate expressed as USD per foreign currency unit (FCU).

The payoff to the carry trade strategy is:

$$
z_{t+1}^{C}=\operatorname{sign}\left(i_{t}^{*}-i_{t}\right) z_{t+1}^{L} .
$$

An alternative way to implement the carry trade is to use forward contracts. We denote by $F_{t}$ the time- $t$ forward exchange rate for contracts that mature at time $t+1$, expressed as USD per FCU. A currency is said to be at a forward premium relative to the USD if $F_{t}$ exceeds $S_{t}$. The carry trade can be implemented by selling forward currencies that are at a forward premium and buying forward currencies that are at a forward discount. The time $t$ payoff to this strategy can be written as:

$$
z_{t+1}^{F}=\operatorname{sign}\left(F_{t}-S_{t}\right)\left(F_{t}-S_{t+1}\right) .
$$

It is easy to show that, when covered interest parity (CIP) holds, these two ways of implementing the carry trade are equivalent in the sense that $z_{t+1}^{C}$ and $z_{t+1}^{F}$ are proportional. ${ }^{3}$ So, whenever one strategy makes positive profits so does the other.

\footnotetext{
${ }^{3}$ Taking transactions costs into account, deviations from CIP are generally small and rare. See Taylor (1987, 1989), Clinton (1988), and Burnside, Eichenbaum, Kleschelski and Rebelo (2006). However, there were significant deviations from CIP in the aftermath of the 2008 financial crisis. These deviations are likely to have resulted from liquidity issues and counterparty risk. See Mancini-Griffoli and Ranaldo (2011) for a discussion.
} 
The portfolio carry trade strategy that we consider combines all the individual carry trades in an equally-weighted portfolio. The total value of the bet is normalized to one USD. We refer to this strategy as the "carry trade portfolio." It is the same as the equally-weighted strategy studied by Burnside et al. (2011).

The momentum strategy This strategy involves selling (buying) a FCU forward if it was profitable to sell (buy) a FCU forward at time $t-\tau$. Following Lustig et al. (2009), Menkhoff et al. (2011a), Moskowitz et al. (2010), and Rafferty (2010), we define momentum in terms of the previous month's return, i.e. we choose $\tau=1$. The excess return to the momentum strategy is:

$$
z_{t+1}^{M}=\operatorname{sign}\left(z_{t}^{L}\right) z_{t+1}^{L}
$$

We consider momentum trades conducted one currency at a time against the U.S. dollar. We also consider a portfolio momentum strategy that combines all the individual momentum trades in an equally-weighted portfolio with the total value of the bet being normalized to one USD. We refer to this strategy as the "momentum portfolio." 4

\subsection{The payoffs to carry and momentum}

Table 1 provides summary statistics for the payoffs to our two currency strategies implemented for 20 major currencies, over the sample period $1976-2010 .^{5}$ In every case, the size of the bet is normalized to one USD.

The carry trade strategy Consider, first, the equally-weighted carry trade strategy. This strategy has an average payoff of 4.6 percent, with a standard deviation of 5.1 percent, and a Sharpe ratio of 0.89 . In comparison, the average excess return to the U.S. stock market

\footnotetext{
${ }^{4}$ The strategy we consider differs from some momentum strategies studied in the literature, which consist of going long (short) on assets that have done relatively well (poorly) in the recent past, even if the return to these assets was negative (positive). See Jegadeesh \& Titman (1993), Carhart (1997), and Rouwenhorst (1998) for a discussion of this cross-sectional momentum strategy in equity markets.

${ }^{5}$ See Burnside et al. (2011) for a description of our data sources.
} 
over the same period is 6.5 percent, with a standard deviation of 15.7 percent and a Sharpe ratio of 0.41 .

Consider, next, the average payoff to the individual carry trades. Averaged across the 20 currencies, this payoff is 4.6 percent with an average standard deviation of 11.3 percent. ${ }^{6}$ The corresponding Sharpe ratio is 0.42 . The Sharpe ratio of the equally-weighted carry trade is more than twice as large. Consistent with Burnside et al. (2007, 2008), this difference is entirely attributable to the gains of diversifying across currencies, which cuts volatility by more than 50 percent.

The momentum strategy The equally-weighted momentum strategy is also highly profitable, yielding an average payoff of 4.5 percent. These payoffs have a standard deviation of 7.3 percent and a Sharpe ratio of 0.62. Again, there are substantial returns to diversifying across individual momentum strategies. The average payoff of individual momentum strategies across the 20 currencies is equal to 4.9 percent. The corresponding average standard deviation is 11.3 percent and the Sharpe ratio is 0.43 . An equally-weighted combination of the two currency strategies, which we call the "50-50 strategy", has an average payoff of 4.5 percent, a standard deviation of 4.6 percent and a Sharpe ratio of 0.98 . The high Sharpe ratio of the combined strategy reflects the low correlation between the payoffs to the two strategies.

Figure 1 displays the cumulative returns to investing in the carry and momentum portfolios, in the U.S. stock market, and in Treasury bills. Since the currency strategies involve zero net investment we compute the cumulative payoffs as follows. We initially deposit one USD in a bank account that yields the same rate of return as the Treasury bill rate. In the beginning of every period we bet the balance of the bank account on the strategy. At the end of the period, payoffs to the strategy are deposited into the bank account. Figure 1 shows that the cumulative returns to the carry and momentum portfolios are almost as

\footnotetext{
${ }^{6}$ The average payoff across individual carry trades does not (to two digits) coincide with the average payoff to the equally-weighted portfolio because not all currencies are available for the full sample.
} 
high as the cumulative return to investing in stocks. By the end of the sample the carry trade, momentum, and stock portfolios are worth $\$ 30.09, \$ 27.98$, and $\$ 40.22$, respectively. However, the cumulative returns to the stock market are much more volatile than those of the currency portfolios. Also, note that most of the returns to holding stocks occur prior to the year 2000. An investor holding the market portfolio from the end of August 2000 until December 2010 earned a cumulative return of only 14.9 percent. Investors in risk-free assets, carry, and momentum earned cumulative returns of 26.7 percent, 93.9 percent, and 76.1 percent, respectively, over the same period.

The payoffs to currency strategies are often characterized as being highly skewed (see e.g. Brunnermeier et al., 2009). Our point estimates indicate that carry trade payoffs are skewed, but this skewness is not statistically significant. Interestingly, carry trade payoffs are less skewed than the payoffs to the U.S. stock market. The payoffs to the momentum portfolio are actually positively skewed, though not significantly so.

As far as fat tails are concerned, currency returns display excess kurtosis, with noticeable central peakedness, especially in the case of the carry trade portfolio. It is not obvious, however, that investors would be deterred by this kurtosis, given the relatively small variance of carry trade payoffs, when compared to that of the aggregate stock market. Indeed, Burnside et al. (2006) use a simple portfolio allocation model to show that a hypothetical investor with constant relative risk aversion preferences, and a risk aversion coefficient of five, would allocate three times as much of his portfolio to diversified carry trades as he would to U.S. stocks.

\subsection{Mechanical explanations for why these strategies work}

In this section, we relate the observed profitability of the carry trade and momentum strategies to the empirical failure of UIP. The payoffs to the strategies can each be written as:

$$
z_{t+1}=u_{t} z_{t+1}^{L}
$$

The two strategies differ only in the definition of $u_{t}$. 
Consider, first, the case in which agents are risk neutral about nominal payoffs. In this case the conditional expected return to taking a long position in foreign currency should be zero, i.e.

$$
E_{t}\left(z_{t+1}^{L}\right)=E_{t}\left[\left(1+i_{t}^{*}\right) \frac{S_{t+1}}{S_{t}}-\left(1+i_{t}\right)\right]=0 .
$$

This is the UIP condition. When this condition holds neither strategy generates positive average payoffs because $E_{t}\left(z_{t+1}\right)=u_{t} E_{t}\left(z_{t+1}^{L}\right)=0$, and, therefore, $E\left(z_{t+1}^{L}\right)=0$.

CIP and UIP, together, imply that the forward exchange rate is an unbiased forecaster of the future spot exchange rate, i.e. $F_{t}=E_{t}\left(S_{t+1}\right)$. It has been known since Bilson (1981) and Fama (1984) that forward-rate unbiasedness fails empirically. So, we should not be surprised that both currency strategies yield non-zero average profits. However, the two strategies differ subtly in how they exploit the fact that the forward is not an unbiased predictor of the future spot.

To see why the carry trade has positive expected payoffs recall the classic result of Meese \& Rogoff (1983) that the spot exchange rate is well approximated by a martingale:

$$
E_{t} S_{t+1} \cong S_{t}
$$

Equations (7) and (3) imply that the expected value of the payoff to the carry trade is:

$$
E_{t}\left(z_{t+1}^{F}\right) \cong\left|F_{t}-S_{t}\right|>0
$$

So, the carry trade makes positive average profits as long as there is a difference between the forward and spot rates, or, equivalently, an interest rate differential between the domestic currency and the foreign currency.

To gain further insight into the average profitability of the carry trade, note that in our sample:

$$
\operatorname{Pr}\left[\operatorname{sign}\left(z_{t+1}^{L}\right)=\operatorname{sign}\left(S_{t}-F_{t}\right)\right]=0.571
$$

So, the probability that the carry trade is profitable is 0.571 . This profitability reflects the ability of the sign of the forward discount to predict the sign of the payoff to a long position in foreign currency. 
The momentum strategy exploits the fact that, at least in sample, there is information in the sign of $z_{t}^{L}$ about the sign of $z_{t+1}^{L}$ :

$$
\operatorname{Pr}\left(\left[\operatorname{sign}\left(z_{t+1}^{L}\right)=\operatorname{sign}\left(z_{t}^{L}\right)\right]=0.569 .\right.
$$

In the next section we turn to the question of whether risk-adjusting the UIP condition can explain the payoffs of the two currency strategies.

\section{Risk and currency strategies}

In this section we argue that the average payoff to our two currency strategies cannot be justified as compensation for exposure to conventional risk factors. We begin by outlining the theory that underlies our estimation strategy. We then describe how we measure the risk exposures of the two currency strategies. Finally, we discuss our empirical findings.

\subsection{Theory}

When agents are risk averse the payoffs to the currency strategies must satisfy:

$$
E_{t}\left(z_{t+1} M_{t+1}\right)=0
$$

Here, $M_{t+1}$ denotes the SDF that prices payoffs denominated in dollars, while $E_{t}$ is the mathematical expectations operator given information available at time $t .^{7}$

The unconditional version of equation (8) is:

$$
E(M z)=0
$$

This equation can be written as:

$$
E(z) E(M)+\operatorname{cov}(z, M)=0
$$

In practice, the average unconditional payoffs to the strategies that we consider are positive. The most straightforward explanation of this finding is that $\operatorname{cov}(z, M)<0$.

\footnotetext{
${ }^{7}$ Most of our analysis is conducted with nominal monthly payoffs. Two of our SDF models are based on real risk factors that are measured at the quarterly frequency. When we work with these models, we follow Burnside et al. (2011) in using quarterly compounded real excess returns to our two strategies.
} 
One can always rationalize the observed payoffs to these strategies by using a statistical model to compute the risk premium as a residual. Consider, for example, the carry trade, in which case we can write equation (8) as:

$$
F_{t}-S_{t}=E_{t}\left(S_{t+1}-S_{t}\right)+p_{t} .
$$

Here, $p_{t}$ is the risk premium which is given by:

$$
p_{t}=\frac{\operatorname{cov}_{t}\left(M_{t+1}, S_{t+1}-S_{t}\right)}{E_{t} M_{t+1}} .
$$

Given a statistical model for $E_{t}\left(S_{t+1}-S_{t}\right)$, we can use equation (11) to back out a time series for $p_{t}$ and call that residual a "risk premium":

$$
p_{t}=F_{t}-S_{t}-E_{t}\left(S_{t+1}-S_{t}\right) .
$$

By construction, this risk premium can rationalize the payoffs to the carry trade. If the spot exchange rate is a martingale, this procedure amounts to labeling the forward premium the risk premium. While such an exercise can provide insights, we view the key challenge as finding observable risk factors that are correlated with the payoffs of the two strategies.

Our analysis uses equation (9) as our point of departure. We consider linear SDFs that take the form:

$$
M_{t}=\xi\left[1-\left(f_{t}-\mu\right)^{\prime} b\right] .
$$

Here $\xi$ is a scalar, $f_{t}$ is a $k \times 1$ vector of risk factors, $\mu=E\left(f_{t}\right)$, and $b$ is a $k \times 1$ vector of parameters. We set $\xi=1$, because $\xi$ is not identified by equation (9). Given this assumption and the model for $M$ given in equation (12), equation (9) can be rewritten as:

$$
E(z)=\operatorname{cov}(z, f) b=\operatorname{cov}(z, f) \Sigma_{f}^{-1} \cdot \Sigma_{f} b=\beta \cdot \lambda,
$$

where $\Sigma_{f}$ is the covariance matrix of $f_{t}$. The betas in equation (13) are population coefficients in a regression of $z_{t}$ on $f_{t}$ and measure the exposure of the payoff to aggregate risk. The $k \times 1$ vector $\lambda$ measures the risk premia associated with the risk factors. 


\subsection{Empirical strategy}

We assess risk-based explanations of the returns to our currency strategies in two ways. First, we ask whether there are risk factors for which the payoffs to the strategies have statistically significant betas. These betas are estimated by running time-series regressions of each portfolio's excess return on a vector of candidate risk factors:

$$
z_{i t}=a_{i}+f_{t}^{\prime} \beta_{i}+\epsilon_{i t}, \quad t=1, \ldots, T, \text { for each } i=1, \ldots, n
$$

Here $T$ is the sample size, and $n$ is the number of portfolios being studied. This step in our analysis is similar in its approach, and in its conclusions, to Villanueva (2007).

Second, we determine whether GMM estimates of a candidate SDF can explain the returns to the carry trade by testing whether equation (9), or, equivalently, equation (13), holds for the estimated model. We estimate the parameters of the SDF, $b$ and $\mu$, using the Generalized Method of Moments (GMM, Hansen 1982), and the moment restrictions (9) and $E(f)=\mu$. Equation $(9)$ can be rewritten as:

$$
E\left\{z\left[1-(f-\mu)^{\prime} b\right]\right\}=0
$$

where $z$ is an $n \times 1$ vector of excess returns. The GMM estimators of $\mu$ and $b$ are $\hat{\mu}=\bar{f}$ and

$$
\hat{b}=\left(d_{T}^{\prime} W_{T} d_{T}\right)^{-1} d_{T}^{\prime} W_{T} \bar{z}
$$

where $d_{T}$ is the sample covariance matrix of $z$ with $f$, and $W_{T}$ is a weighting matrix. ${ }^{8}$ Estimates of $\lambda$ are obtained from $\hat{b}$ as $\hat{\lambda}=\hat{\Sigma}_{f} \hat{b}$, where $\hat{\Sigma}_{f}$ is the sample covariance matrix of $f$. The model's predicted mean returns, $\hat{z}=d_{T} \hat{b}$, are estimates of the right hand side of equation (13). The model $R^{2}$ measures the fit between $\hat{z}$ and $\bar{z}$, the sample average of the mean excess returns. The pricing errors are the residuals, $\hat{\alpha}=\bar{z}-\hat{z}$. We test that the pricing errors are zero using the statistic $J=T \hat{\alpha}^{\prime} V_{T}^{-1} \hat{\alpha}$, where $V_{T}$ is a consistent estimate of the asymptotic covariance matrix of $\sqrt{T} \hat{\alpha}$. The asymptotic distribution of $J$ is $\chi^{2}$ with $n-k$ degrees of freedom.

\footnotetext{
${ }^{8}$ Burnside (2007) provides details of the GMM procedure.
} 
In the first GMM step the weighting matrix is $W_{T}=I_{n}$, and the estimate of $\lambda$ and the pricing errors are the same as the ones obtained by running a cross-sectional regression of average portfolio excess returns on the estimated betas:

$$
\bar{z}_{i}=\hat{\beta}_{i}^{\prime} \lambda+\alpha_{i}, \quad i=1, \ldots, n
$$

Here $\bar{z}_{i}=\frac{1}{T} \sum_{t=1}^{T} z_{i t}, \hat{\beta}_{i}$ is the OLS estimate of $\beta_{i}$, and $\alpha_{i}$ is the pricing error. In subsequent GMM steps the weighting matrix is chosen optimally. Our results are similar at all stages of GMM, so, due to space limitations, we only present results for iterated GMM.

\subsection{Empirical results with conventional risk factors}

In this section we use the empirical methods outlined in the previous section to determine whether there is a candidate SDF that can price the returns to the carry trade and momentum. We consider several models using monthly data: the CAPM (Sharpe 1964, Lintner 1965), the Fama \& French (1993) three factor model, the quadratic CAPM (Harvey \& Siddique, 2000), and a model that uses the CAPM factor, realized stock market volatility, and their interaction, as factors. The latter two models are ones in which the market betas of the assets being studied can be thought of as being time varying. We also consider two models using quarterly data. The first model (the C-CAPM) uses the growth rate of real consumption of nondurables and services as a single factor. This model is a linear approximation to a representative agent model in which households have standard preferences over a single consumption good. The second model (the extended C-CAPM) uses three factors: the growth rate of real consumption of nondurables and services, the growth rate of the service flow from the real stock of durables, and the market return. This model is a linear approximation to a representative agent model in which households have recursive preferences over the two types of consumption good (see Yogo, 2006).

Table 2 summarizes the estimates we obtain by running the time-series regressions described by equation (14) for monthly and quarterly models. In every case, but one, we find that the estimated betas are insignificantly different from zero. The one exception is that 
the beta for the carry trade associated with the market return in the Fama-French three factor model is statistically significant. However, this coefficient is economically small (0.045). Given our estimates of the Fama-French model, the implied annual expected return of the carry trade portfolio should only be 0.3 percent. The actual return is 4.6 percent.

Table 3 presents estimates of the monthly models based on iterated GMM estimation. Table 4 presents analogous results for the quarterly models. The models are estimated using the equally-weighted carry trade and momentum portfolios, as well as Fama and French's 25 portfolios sorted on the basis of book to market value and size. First, note that in every case the pricing errors of the currency strategies are large and statistically significant. So, even though the models have some explanatory power for stocks, none of the models explains currency strategies payoffs. Second, all of the models are rejected, at the 5 percent level, by the pricing error test.

The only model with a reasonably good fit (positive $R^{2}$ ) is the Fama-French model. But it, like the other models, does a very poor job of explaining the returns to the currency portfolios. Figure 2 plots $\hat{z}$, the predictions of the Fama-French model for $E\left(z_{t}\right)$, against $\bar{z}$, the sample average of $z_{t}$. The circles pertain to the Fama-French portfolios, the star pertains to the carry trade portfolio, and the square pertains to the momentum portfolio. Not surprisingly, the model does a reasonably good job of pricing the excess returns to the Fama-French 25 portfolios. However, the model greatly understates the average payoffs to the currency strategies. The annualized average payoff to the carry trade and momentum strategies are 4.6 and 4.5 percent, respectively. The Fama-French model predicts that these average returns should equal 0.2 and -0.2 percent. The solid lines through the star and square are two-standard-error bands for the difference between the data and model average payoff, i.e. the pricing error. Clearly, we can reject the hypothesis that the model accounts for the average payoffs to the currency strategies.

Overall, our results are consistent with those in Villanueva (2007), Burnside et al. (2011), and Burnside (2011), who show that a wider set of conventional risk factors cannot explain 
the returns to the carry trade. Our results show that conventional risk factors also cannot explain the returns to the currency momentum portfolio.

\subsection{Factors derived from currency returns}

We now turn to less traditional risk-factor models in which the factors are derived from the returns to currency strategies. This approach, introduced to the currency literature by Lustig et al. (2009), is similar to the one popularized by Fama \& French (1993) who construct risk factors based on the returns to particular stock strategies.

\subsubsection{Portfolios of currencies sorted by their forward discount}

Following Lustig \& Verdelhan (2007), Lustig et al. (2009), and Menkhoff et al. (2011a) we construct five portfolios, labeled $\mathrm{S} 1, \mathrm{~S} 2, \mathrm{~S} 3, \mathrm{~S} 4$, and $\mathrm{S} 5$, by sorting currencies according to their forward discount against the U.S. dollar (USD). The sorting is done period by period. Each portfolio is equally weighted and represents the excess return to lending at the risk-free rate the currencies included in the portfolio while borrowing USD at the risk free rate.

Table 5 shows that the average return to the portfolios S1-S5 is monotonically increasing. This property is not surprising given Meese \& Rogoff's (1983) result that exchange rates are close to a martingale. If the spot exchange rate for each currency was exactly a martingale, then the conditional mean of each portfolio's return would equal the average forward discount of the constituent currencies. So, for a large enough sample, the sorting procedure would generate portfolios with monotonically increasing average returns.

Consistent with the literature, we attempt to explain the cross-section of returns to these portfolios of currencies, but we add the equally-weighted momentum portfolio to the set of test assets. ${ }^{9}$ By focusing on currency portfolios and excluding stock returns from our analysis, we allow for the possibility that markets are segmented, so that currency traders and stock market investors have different SDFs. That said, factors that explain portfolios

\footnotetext{
${ }^{9}$ We do not add the equally-weighted carry trade portfolio to the cross section because its construction is closely related to that of the S1-S5 portfolios. However, we present betas for the equally-weighted carry trade portfolio. Our cross-sectional results are robust to including this portfolio as one of the test assets.
} 
S1-S5 should also explain the currency momentum portfolio.

\subsubsection{Currency-based risk factors}

Like Lustig et al. (2009), we construct two risk factors directly from the sorted portfolios. The first risk factor, which they call the dollar risk factor and denote by DOL, is simply the average excess return of the five sorted portfolios. The second risk factor, which they denote by $\mathrm{HML}_{\mathrm{FX}}$, is the return differential between the $\mathrm{S} 5$ portfolio (the largest forward discount) and the S1 portfolio (the smallest forward discount). So, HML $\mathrm{Fx}_{\mathrm{X}}$ is the payoff to a carry trade strategy in which we go long in the highest forward-discount currencies and go short in the smallest forward-discount currencies.

Following Menkhoff et. al. (2011a), we construct a measure of global currency volatility, which we denote by VOL. It is measured monthly, and is the average sample standard deviation of the daily log changes in the values of the currencies in our sample against the USD.

\subsubsection{Betas of currency-based factors}

Table 5 summarizes the results of estimating time-series regressions of the monthly excess returns to $\mathrm{S} 1, \mathrm{~S} 2, \mathrm{~S} 3, \mathrm{~S} 4, \mathrm{~S} 5$, the carry trade portfolio and the momentum portfolio on two pairs of risk factors: DOL and $\mathrm{HML}_{\mathrm{FX}}$, and DOL and VOL.

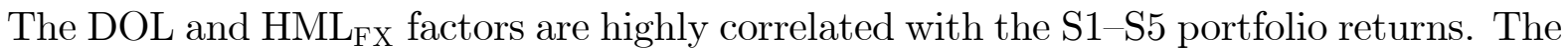
betas on the DOL factor are all close to one in value, and statistically significant. The betas of the $\mathrm{HML}_{\mathrm{Fx}}$ factor rise monotonically from -0.48 for $\mathrm{S} 1$ to 0.52 for $\mathrm{S} 5$. The betas for $\mathrm{S} 2$, $\mathrm{S} 3$ and S4 are close to zero. While the $R^{2}$ for the five regressions are large, this result is not particularly surprising. Sorting portfolios on the basis of the forward discount produces a monotonic ordering of the expected returns. So, the DOL and $\mathrm{HML}_{\mathrm{FX}}$ factors create, by construction, a pattern in the betas similar to that in Table $5 .{ }^{10}$ DOL and HML $\mathrm{Fx}$ also have positive and significant betas for the equally-weighted carry trade portfolio, but the $R^{2}$ is

\footnotetext{
${ }^{10}$ See Burnside (2011) for a detailed discussion.
} 
much lower in this case. Finally, neither factor has a significant beta for the momentum portfolio.

Replacing $\mathrm{HML}_{\mathrm{Fx}}$ with VOL as a factor has very little impact on the betas with respect to DOL. The betas with respect to VOL decrease monotonically as we go from S1 to S5 and are statistically significant for the extreme portfolios, being positive for S1 and negative for S5. These findings indicate that when global currency volatility increases, the returns to holding low-interest rate currencies increase and the returns to holding high-interest rate currencies decrease. That is, low interest rate currencies provide a hedge against increases in volatility. The beta with respect to VOL is also negative and statistically significant for the carry trade portfolio. The beta with respect to VOL is positive but insignificant for the currency momentum portfolio.

\subsubsection{Cross-sectional analysis of currency-based risk factors}

Table 6 presents iterated GMM estimates of the SDF for the two currency-based factor models, using portfolios S1-S5 and the momentum portfolio as test assets. Figure 3 shows the mean returns in the sample plotted against the model-predicted expected returns.

In both cases, the $b$ parameter associated with the DOL factor is statistically insignificant. The risk premium, $\lambda_{\mathrm{DOL}}$, is positive and significant in one case. But in neither case does exposure to DOL explain much of the variation in expected return across portfolios.

The $b$ and $\lambda$ parameters associated with the $\mathrm{HML}_{\mathrm{Fx}}$ factor are positive and statistically significant at the 5 percent level. The $b$ and $\lambda$ parameters associated with the VOL factor are negative and statistically significant at the 5 percent level.

Neither the DOL-HML $F$ model nor the DOL-VOL model do a good job of fitting the overall cross section of average payoffs to the currency strategies. The $R^{2}$ is lower than 0.04 for both models. The DOL-HML $\mathrm{Fx}$ model is rejected on the basis of the pricing-error test. The DOL-VOL model is not rejected. But this apparent success is mostly due to the model's parameters being estimated with less precision than those of the $\mathrm{HML}_{\mathrm{FX}}$-based model.

The primary failing of both models is the large pricing error associated with momentum 
(approximately 5 percent). To understand this failing recall that the average payoff to the momentum strategy is 4.5 percent. The DOL-HML $\mathrm{Fx}$ cannot explain this large payoff because momentum's beta is close to zero with respect to DOL and a negative with respect to $\mathrm{HML}_{\mathrm{Fx}}$. The DOL-VOL model does no better because it has a paradoxically positive (but poorly estimated) beta with respect to VOL, i.e. momentum is a good hedge against volatility. Menkhoff et al. (2011a) find a similar paradox using a set of sorted momentum portfolios.

\subsection{Concluding discussion}

The results in this section suggest that observable risk factors explain very little of the average returns to the carry trade and momentum portfolios, resulting in economically large pricing errors. In every case the models can also be rejected based on statistical tests of the pricing errors. Models built from currency specific factors do have some success in explaining the returns to the carry trade. But, they do not explain the returns to the momentum portfolio.

\section{$4 \quad$ Rare disasters and peso problems}

Authors such as Jurek (2008), Farhi \& Gabaix (2008), Farhi et al. (2009), and Burnside et al. (2011) have argued that the payoffs to the carry trade can, at least in part, be explained by the presence of rare disasters or peso problems. ${ }^{11}$ By rare disasters we mean very low probability events that sharply decrease the payoff and/or sharply increase the value of the SDF. These events may occur in sample. But, due to their low probability, they may be under-represented relative to their true frequency in population. By a peso problem we mean an extreme form of this problem, where rare disasters do not occur in sample.

\footnotetext{
${ }^{11}$ In this review we focus on recent work that uses options data to study the importance of rare disasters and peso problems. See Evans (2011) for an excellent overview of the earlier literature that uses survey data and regime-switching models to study how peso problems affect conditional inference about the behavior of exchange rates.
} 
Rare disasters We study the effects of rare disasters on inference using a simple model. Let $\omega \in \Omega$ denote the state of the world, let $z(\omega)$ denote the payoff to a currency strategy in state $\omega$, and $M(\omega)$ denote the value of the SDF in state $\omega$. We partition $\Omega$, the set of possible states, into two sets. The first set, $\Omega^{N}$, consists of those values of $\omega$ corresponding to non-rare-disaster (normal) events. The second set, $\Omega^{D}$, consists of those values of $\omega$ corresponding to a rare-disaster event. For simplicity, we assume that $\Omega^{D}$ contains a single event, $\omega^{D}$. We use the notation $M^{\prime}=M\left(\omega^{D}\right)$ and $z^{\prime}=z\left(\omega^{D}\right)$, and assume that $z^{\prime}<0$. To simplify, we assume that the conditional and unconditional probability of the rare disaster is $p$.

Payoffs to a currency strategy must satisfy:

$$
(1-p) E^{N}(M z)+p M^{\prime} z^{\prime}=0
$$

where $E^{N}(\cdot)$ denotes the expectation over normal states. Since the scale of $M$ is not identified for zero net investment strategies, we choose the normalization $E^{N}(M)=1$.

How can rare disasters explain the profitability of a currency strategy? Assume, for simplicity, that an econometrician can observe $M$ and $z$ and that the sample average of $M z$ across normal events in the sample equals $E^{N}(M z)$. Suppose that in sample rare disasters occur with frequency $\hat{p}<p$. Since $z^{\prime}<0$, the overall sample average of $M z$ is positive, even though the true unconditional value is zero:

$$
(1-\hat{p}) E^{N}(M z)+\hat{p} M^{\prime} z^{\prime}=(p-\hat{p})\left[E^{N}(M z)-M^{\prime} z^{\prime}\right]>0 .
$$

How likely are we to observe an unusually small number of rare disasters in sample? Consider the value of $p$ suggested by Nakamura et al. (2010). These authors define a rare disaster as a large drop in consumption. Using data spanning 24 countries and more than 100 years, they estimate the annual probability of a disaster to be 0.017 . The corresponding monthly value of $p$ is 0.0014 .

Since most work on currency strategies focuses on the post Bretton-Woods era, we think of a typical sample size as roughly $(2011-1973) \times 12=456$ months. For $p=0.0014$, the 
expected number of events in a sample of this size is less than one. Indeed, the probability of observing zero rare disasters in a sample of 456 months is roughly 53 percent.

Can we interpret particular in-sample events as realizations of the rare disaster event that accounts for the observed profitability of the carry trade and momentum strategies? For example, was the 2008 financial crisis an example of such a rare disaster? The answer is no. To see why, note that equation (18) implies that the ratio of risk-adjusted mean payoffs in the normal states must be equal to the ratio of the payoffs in the disaster state:

$$
\frac{E^{N}\left(M z_{1}\right)}{E^{N}\left(M z_{2}\right)}=\frac{z_{1}^{\prime}}{z_{2}^{\prime}} .
$$

Here, $z_{1}^{\prime}$ and $z_{2}^{\prime}$ denote the payoffs to the carry trade and momentum strategy in the disaster state. We define the disaster period to be August-November 2008 because, during this period, the carry trade suffered a cumulative net loss of about 10 percent, its worst loss over a four month period in our sample. In contrast, the momentum strategy had a cumulative gain of about 24 percent in this period, its largest over a four month period in our sample. So the ratio on the right hand side of equation (19) is negative. Since the average risk-adjusted profits of both strategies are positive outside of the crisis period, the left hand side of equation (19) is positive. So, the financial crisis is not a plausible example of a rare-disaster event that accounts for the profitability of the carry trade and momentum strategies. Neither are other periods in our sample (early 1991, and late 1992) when carry trades took heavy losses. In these periods the momentum strategy was also highly profitable.

There are two ways to avoid the conclusion that the recent financial crisis is not the type of rare disaster that accounts for the profitability of the carry trade and momentum strategies. The first is to assume that, because of market segmentation, $M^{\prime}$ is different for the two currency trading strategies. This hypothesis seems very implausible. The second is to assume that $\Omega^{D}$ contains more than one event, and not all strategies earn negative returns in all of these events. So the financial crisis could be viewed as a rare disaster in which the carry trade has a negative payoff but momentum does not. We cannot rule out this explanation on logical grounds. But it leaves unexplained the in-sample profitability of 
the momentum strategy.

Peso problems Recall that a peso problem corresponds to the case where there are no raredisasters in sample, so $\hat{p}=0$. Absent additional assumptions, the peso-problem explanation of the profitability of our two strategies has no testable implications, since $z^{\prime}$ is not observed. To generate testable implications we assume, as above, that there is a single peso event. We can then use data on currency options to develop a test of the peso-problem hypothesis.

Investors can use options to construct hedged versions of currency strategies that are exposed to disaster risk. These hedged strategies put an upper bound on an investor's possible losses. Suppose a currency strategy involves going long (short) on foreign currency. Then this strategy is exposed to large losses if there is a large depreciation (appreciation) of the foreign currency. By buying a put (call) option on foreign currency the investor can bound these losses. The payoff to a hedged strategy, $z_{t+1}^{H}$, is given by

$$
z_{t+1}^{H}= \begin{cases}h_{t+1} & \text { if the option is in the money } \\ z_{t+1}-c_{t}\left(1+i_{t}\right) & \text { if the option is out of the money. }\end{cases}
$$

The variables $c_{t}$ and $i_{t}$ denote the cost of the put or call option and $i_{t}$ denotes the nominal interest rate. The variable $h_{t+1}$ is the lower bound on the investor's net payoff.

Since the hedged strategy is also a zero net-investment strategy, its payoff, $z^{H}$, must satisfy:

$$
(1-p) E^{N}\left(M z^{H}\right)+p M^{\prime} E^{N}(h)=0 .
$$

Using equation (20) to solve for $p M^{\prime}$ and replacing this term in equation (18), we obtain:

$$
z^{\prime}=E^{N}(h) \frac{E^{N}(M z)}{E^{N}\left(M z^{H}\right)} .
$$

Motivated by our previous results we assume that $\operatorname{cov}^{N}(M, z)=\operatorname{cov}^{N}\left(M, z^{H}\right)=0$. Then equation (21) simplifies to:

$$
z^{\prime}=E^{N}(h) \frac{E^{N}(z)}{E^{N}\left(z^{H}\right)} .
$$


Using equations (18) and (20) we can derive two expressions for $\rho \equiv p M^{\prime} /(1-p)$ that are numerically identical given our method of estimating $z^{\prime}$ :

$$
\rho=-\frac{E^{N}(z)}{z^{\prime}}=-\frac{E^{N}\left(z^{H}\right)}{E^{N}(h)} .
$$

Here, we estimate $\rho$ because the parameters $p$ and $M^{\prime}$ are not separately identified by the pricing equations.

We estimate $z^{\prime}$ and $\rho$ for the carry trade using currency option data from J.P. Morgan for ten major currencies over the period 1995-2009. As in Burnside et al. (2011), we assume that in the disaster state all of the individual currency carry trades lose money. Consequently, we assume that the investor hedges the equally-weighted carry trade strategy by buying at-the-money options. This assumption means that the payoff of the carry trade portfolio in the peso state is the average of the minimum payoffs of the individual carry trades in that state.

The momentum strategy for an individual currency sometimes takes the opposite position of the carry trade strategy. In these instances, if we assume carry is exposed to disaster risk, momentum is naturally hedged against it. This property presents a difficulty for our empirical strategy because it means that the unhedged momentum payoff for an individual currency in the disaster state is occasionally $-z^{\prime}$, rather than $z^{\prime}$.

To bring momentum into our analysis, we consider a 50-50 portfolio that equally combines the carry trade and momentum portfolios. Suppose each of these portfolios is formed with $n$ currencies. When the two underlying strategies agree on the sign of an individual currency trade, the net position in the portfolio for that currency is $\pm 1 / n$. In this case, the position is naturally exposed to disaster risk, and this risk can be hedged using options. When the two underlying strategies disagree on the sign of an individual currency trade, the net position for that currency is zero.

Using data on the payoffs to the hedged and unhedged carry trade and 50-50 carrymomentum strategies, and data on the minimum payoffs to the hedged strategies, we estimate the moments that appear on the right hand sides of equations (22) and (23). Doing so 
provides us with estimates of $z_{1}^{\prime}$ (the payoff to the equally-weighted carry trade in the disaster state) and $z_{2}^{\prime}$ (the payoff to the 50-50 strategy in the disaster state), and two estimates of $\rho$. Using a Wald test, we can test whether the two estimates of $\rho$ are equal, which they should be, in absence of market segmentation. ${ }^{12}$ Alternatively, we can use the pricing equations of the hedged and unhedged versions of the two strategies to estimate the three parameters, $z_{1}^{\prime}$ and $z_{2}^{\prime}$ and $\rho$ using GMM. This system is overidentified, and, therefore, provides us with a simple test of the peso problem hypothesis.

When we use the first procedure, our estimates are $z_{1}^{\prime}=-0.037(0.014), z_{2}^{\prime}=-0.019$ (0.006). Standard errors are reported in parenthesis. Our two estimates of $\rho$ are 0.095 (0.059) and 0.159 (0.091). The two estimates of $\rho$ are insignificantly different from each other according to the Wald test $(\mathrm{p}$-value $=0.23)$. Given the small standard errors associated with $z_{1}^{\prime}$ and $z_{2}^{\prime}$, we can be quite confident that the disaster event is not characterized by large losses to either the carry trade or the 50-50 carry-momentum portfolio.

When we use the second procedure, our estimates of $z_{1}^{\prime}$ and $z_{2}^{\prime}$ are $-0.040(0.020)$ and -0.027 (0.015), and our estimate of $\rho$ is $0.089(0.064)$. The test of the overidentifying restrictions does not reject the model $(\mathrm{p}$-value $=0.27)$. A value of $\rho$ of 0.089 means that if we assume that the true probability of a rare event is $p=0.0014$, then $M^{\prime} \cong 63$.

Our analysis assumes that the SDF takes on a single value in the rare disaster or peso state. Under alternative assumptions, we can still generate testable implications of the peso problem hypothesis. For example, Burnside et al. (2011) show how to estimate a lower bound for $E^{D}\left(z_{1}\right)$ allowing for negative covariance between payoffs to the carry trade and the SDF in the peso state.

Overall, we find little evidence against the peso event hypothesis. According to our point estimates, the peso event is not characterized by large losses to the currency strategies. Instead, it is characterized by moderate losses and large values of the SDF.

\footnotetext{
${ }^{12}$ Burnside et al. (2011) discuss a related comparison of the values of $M^{\prime}$ implied by the carry trade and a hedged stock market strategy.
} 


\section{Price pressure}

In this section we discuss an alternative explanation for the profitability of our currency strategies raised in Burnside et al. (2006). This explanation relies on the existence of price pressure in the foreign exchange market. By price pressure we mean that the price at which investors can buy or sell an asset depends on the quantity they wish to transact. There is a strand of research in finance that stresses the possibility that demand curves for assets are downward sloping. Shleifer (1986) and Mitchell \& Pulvino (2004) present evidence in support of this view for stocks.

Anecdotal evidence gathered from currency traders suggests that a similar phenomenon occurs in foreign exchange markets: prices move against individual traders when they place large orders. Here we present a simple model that illustrates the implications of price pressure for the profitability of currency-trading strategies.

The case of a single trader Consider an asset that has a value $v+\varepsilon$, where $\varepsilon$ is a random variable with mean zero. Suppose that there is a single risk-neutral trader who decides to buy $x$ units of the asset. To capture the basic effects of price pressure we suppose that the price of the asset that the trader purchases depends on order size in the following way. The price in the beginning of the day is:

$$
p_{0}=a
$$

As long as $a<v$, it is optimal for the trader to buy a positive quantity of the asset. Trading takes place during the course of a day. At instant $t$ during the day the change in the price depends on the quantity of orders, $m_{t}$, submitted at that point in time:

$$
\dot{p}_{t}=b m_{t} \text {. }
$$

We assume that $b$ is positive, so that the price is an increasing function of the quantity purchased, i.e., there is price pressure.

Suppose the trader wants to buy $x$ units of currency during the day. Consider the 
following two strategies. Strategy A is to submit an order for $x$, say, at the end of the day. The price associated with the order is $a+b x$, so that the total cost of the order is: $x(a+b x)$.

Strategy B is to break up the order and submit orders of size $m=x / T$ throughout the day. Here, $T$ is the number of trading minutes in the day. The price of the asset at time $t$ is given by:

$$
p_{t}=a+b \int_{0}^{t} m_{s} d s=a+b \frac{x}{T} t .
$$

The total cost of the order is:

$$
\int_{0}^{T} p_{t} \frac{x}{T} d t=a x+b \frac{1}{2} x^{2} .
$$

It is clear that, from the perspective of the trader, strategy B dominates strategy A. So, we assume that the trader uses strategy B and breaks up the orders. It is useful to re-write the total cost of the order as: $\int_{0}^{x}(a+b z) d z$.

The trader's profit, $\pi$, is given by:

$$
\pi=(v+\varepsilon) x-\int_{0}^{x}(a+b z) d z .
$$

The trader chooses $x$ to maximize the expected value of $\pi$ :

$$
E(\pi)=v x-\int_{0}^{x}(a+b z) d z .
$$

The first-order condition for this problem implies that the optimal value of $x, x^{*}$, is given by:

$$
x^{*}=\frac{v-a}{b} .
$$

The price paid for the last unit of the asset purchased is:

$$
p^{*}=v
$$

We wish to stress two key features of this example. First, the expected profit from the last unit of the asset purchased by the trader is equal to zero. Second, the total expected profits earned by the trader are positive:

$$
E(\pi)=\frac{1}{2} \frac{(v-a)^{2}}{b} .
$$


Consider an econometrician who observes the average trade during the day. He would correctly infer that the strategy is profitable. Suppose that he ignores the existence of price pressure and assumes that marginal and average profits coincide. Then he would incorrectly conclude that the trader is leaving money on the table by not expanding the size of the trade.

The case of $\mathbf{n}$ traders Suppose that there is a fixed number, $n$, of traders. Within the day price pressure is governed by equations (24) and (25) where $m_{t}$ denotes total orders arriving at time $t$. Consider a Nash equilibrium in which each trader chooses to buy $x$ units of the asset taking as given that the remaining $n-1$ traders buy $\bar{x}$ units each. The order in which trades occur is randomly determined after traders choose $x$. Trader $j$ trades from time $T(j-1) / n$ to time $T j / n$, where the index $j$ takes values from one to $n$. Each trader breaks up his orders uniformly within his trading period. Since a representative trader has a probability $1 / n$ of being the $j$ th trader, his expected profit is:

$$
E(\pi)=v x-\sum_{j=0}^{n-1} \frac{1}{n} \int_{j \bar{x}}^{j \bar{x}+x}(a+b z) d z .
$$

The optimal value of $x$ satisfies the first-order condition:

$$
v=a+b x+\frac{1}{2} b \bar{x}(n-1)
$$

In a symmetric equilibrium $x=\bar{x}$, so:

$$
x=\frac{2(v-a)}{b(1+n)} .
$$

The average expected profit across traders is positive and equal to:

$$
E(\pi)=\frac{2(v-a)^{2}}{b(1+n)^{2}}>0
$$

The expected profit of a trader who has a position $j$ in the trading queue is:

$$
E\left(\pi_{j}\right)=\frac{2}{b} \frac{(v-a)^{2}}{(1+n)^{2}}[n+2(1-j)]
$$


So, when $n$ is large, roughly half of the traders make profits and the other half make losses. The profits of the winners are larger than the losses of the losers, which is why average profits across traders are positive.

As in the single trader case, an econometrician who observes the average trade during the day would conclude that the strategy is profitable. He might wonder why traders don't increase their positions until this profitability vanishes. But, while the average trade generates profits, the marginal trade makes losses. So, there is no reason for traders to expand their positions. No money is being left on the table.

\section{Conclusion}

We discuss two conventional explanations for the apparent profitability of the carry trade and momentum strategies. The first is that investors are compensated for the risk they bear. While this hypothesis is very appealing, we find little evidence to support it. The second conventional explanation is that the profitability of the two currency strategies results from a rare disaster or peso problem. We argue that the recent financial crisis is not a rare disaster from the standpoint of a currency speculator who uses both the carry trade and momentum strategies. We also argue that the peso event is not characterized by large losses to currency speculators. Instead, it features moderate losses and high values of the stochastic discount factor.

Finally, we discuss the potential role of price pressure in explaining the profitability of the two currency strategies. While this approach shows some promise, two important questions remain to be answered. First, is the form of price pressure postulated in our example empirically plausible for currency markets? Second, what is the source of this price pressure? 


\section{Literature Cited}

Asness CS, Moskowitz TJ, Pedersen LH. 2009. Value and momentum everywhere. Mimeo, University of Chicago.

Backus DK, Foresi S, Telmer CI. 2001. Affine term structure models and the forward premium anomaly. J. Financ. 56(1):279-304.

Bekaert G, Hodrick RJ. 1992. Characterizing predictable components in excess returns on equity and foreign exchange markets. J. Financ. 47(2):467-509.

Bilson JFO. 1981. The 'Speculative Efficiency' hypothesis. J. Bus. 54(3):435-51.

Brunnermeier MK, Nagel S, Pedersen LH. 2009. Carry trades and currency crashes. NBER Macroecon. Ann. 23:313-47.

Burnside C. 2007. The cross-section of foreign currency risk premia and consumption growth risk: A comment. NBER Working Paper 13129.

Burnside C. 2011. Carry trades and risk. Forthcoming in The Handbook of Exchange Rates, James J, Marsh IW, Sarno L, eds. Hoboken, NJ: Wiley

Burnside C, Eichenbaum M, Kleshchelski I, Rebelo S. 2006. The returns to currency speculation. NBER Working Paper 12489.

Burnside C, Eichenbaum M, Kleshchelski I, Rebelo S. 2011. Do peso problems explain the returns to the carry trade? Rev. Financ. Stud. 24(3):853-91.

Burnside C, Eichenbaum M, Rebelo S. 2007. The returns to currency speculation in emerging markets. Am. Econ. Assoc. 97(2):333-8.

Burnside C, Eichenbaum M, Rebelo S. 2008, Carry trade: The gains of diversification. $J$. Eur. Econ. Assoc. 6(2-3):581-8. 
Carhart M. 1997. On persistence in mutual fund performance. J. Financ. 52(1):57-82.

Clinton K. 1988. Transactions costs and covered interest arbitrage: Theory and evidence. J. Polit. Econ. 96(2):358-70.

Engel C. 1996. The forward discount anomaly and the risk premium: A survey of recent evidence. J. Empir. Financ. 3(2):123-92.

Evans, M. 2011. Exchange rate dynamics. Princeton University Press.

Fama EF. 1984. Forward and spot exchange rates. J. Monetary Econ. 14(3):319-38.

Fama EF, French KR. 1993. Common risk factors in the returns on stocks and bonds. J. Financ. Econ. 33(1):3-56.

Farhi E, Fraiberger SP, Gabaix X, Ranciere R, Verdelhan A. 2009. Crash risk in currency markets. NBER Working Paper 15062.

Farhi E, Gabaix X. 2008. Rare disasters and exchange rates. NBER Working Paper 13805.

Hansen LP. 1982. Large sample properties of generalized method of moments estimators. Econometrica 50(4):1029-54.

Harvey CR, Siddique A. 2000. Conditional skewness in asset pricing tests. J. Financ. $55(3): 1263-95$.

Hodrick RJ. 1987. The Empirical Evidence on the Efficiency of Forward and Futures Foreign Exchange Markets. Chur, Switzerland: Harwood Academic Publishers

Jegadeesh N, Titman S. 1993. Returns to buying winners and selling losers: Implications for stock market efficiency. J. Financ. 48(1):65-91.

Jordà Ò, Taylor AM. 2009. The carry trade and fundamentals: Nothing to fear but FEER itself. NBER Working Paper 15518. 
Jurek JW. 2008. Crash-neutral currency carry trades. Mimeo, Princeton University. SSRN Paper 1262934.

Lintner J. 1965. The valuation of risk assets and the selection of risky investments in stock portfolios and capital budgets. Rev. Econ. Stat. 47(1):13-37.

Lustig H, Roussanov N, Verdelhan A. 2009. Common risk factors in currency markets. SSRN Paper 1139447.

Lustig H, Verdelhan A. 2007. The cross-section of foreign currency risk premia and consumption growth risk. Am. Econ. Rev. 97(1):89-117.

Mancini-Griffoli T, Ranaldo A. 2011. Limits to arbitrage during the crisis: funding liquidity constraints and covered interest parity. SSRN Paper 1549668.

Meese RA, Rogoff K. 1983. Empirical exchange rate models of the seventies: Do they fit out of sample? J. Int. Econ. 14(1-2):3-24.

Menkhoff L, Sarno L, Schmeling M, Schrimpf A. 2011a. Carry trades and global foreign exchange volatility. Forthcoming, J. Financ.

Menkhoff L, Sarno L, Schmeling M, Schrimpf A. 2011b. Currency momentum strategies. Mimeo. Cass Business School, City University, London.

Mitchell M, Pulvino T. 2004. Price pressure around mergers. J. Financ. 59(1):31-63.

Moskowitz T, Ooi YH, Pedersen LH. 2010. Time series momentum. Mimeo, New York University.

Nakamura E, Steinsson J, Barro RJ, Ursúa JF. 2010. Crises and recoveries in an empirical model of consumption disasters. NBER Working Paper 15920.

Okunev J, White D. 2003. Do momentum-based strategies still work in foreign currency markets? J. Financ. Quant. Anal. 38(2):425-47. 
Rafferty B. 2010. The returns to currency speculation and global currency realignment risk. Mimeo, Duke University.

Rouwenhorst KG. 1998. International momentum strategies. J. Financ. 53(1):267-84.

Sharpe WF. 1964. Capital asset prices: a theory of market equilibrium under conditions of risk. J. Financ. 19(3):425-42.

Shleifer A. 1986. Do demand curves for stocks slope down? J. Financ. 41(3):579-90.

Taylor, MP. 1987. Covered interest parity: A high-frequency, high-quality data study. Economica 54 (216):429-38.

Taylor, MP. 1989. Covered interest arbitrage and market turbulence. Econ. J. 99(396):37691.

Villanueva OM. 2007. Forecasting currency excess returns: Can the forward bias be exploited? J. Financ. Quant. Anal. 42(4):963-90.

Yogo M. 2006. A consumption-based explanation of expected stock returns. J. Financ. 61(2):539-80. 
Figure 1: Cumulative Returns of Investment Strategies, Feb. 1976-Dec. 2010

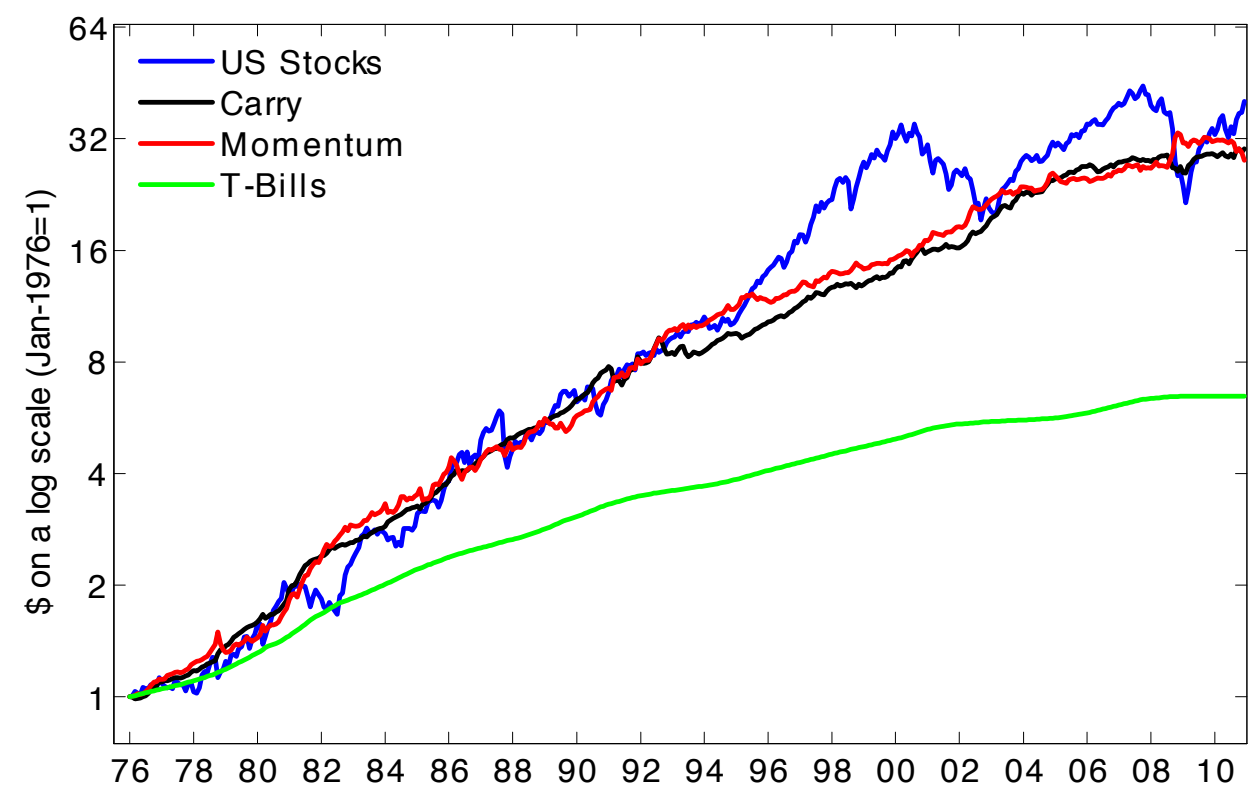

Note: The figure plots the cumulative returns of a trader who begins with 1 dollar in January 1976 and invests his accumulated earnings exclusively in one of four strategies. For T-bills and US stocks we use the risk free rate and value-weighted market return reported in Kenneth French's database. Details for the carry trade and momentum strageties are provided in the text. 


\section{Figure 2: Cross-Sectional Fit of the Fama-French Model}

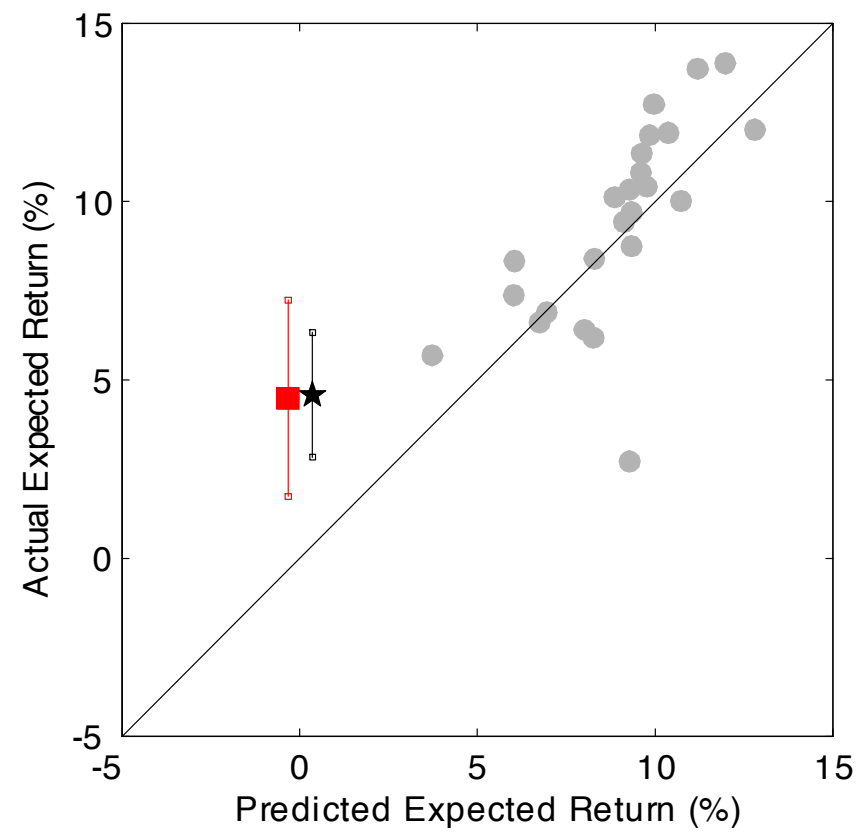

Note: For each portfolio, the graph plots the average annualized payoffs of each portfolio, $\bar{x}$ (on the y-axis), against the model-predicted mean return, $\hat{z}$ (on the x-axis). The gray dots correspond to Fama and French's 25 portfolios sorted on the basis of book-to-market value and firm size. The black star represents the carry-trade portfolio. The red square represents the momentum portfolio. The vertical lines extending above and below the star and square are two-standard error bands for each portfolio's pricing error. When these lines do not cross the 45 degree line, the pricing error is statistically significant at the 5 percent level. 
Figure 3: Cross-Sectional Fit of the Currency-Based Factor Models

(a) Model 1: DOL and $\mathrm{HML}_{\mathrm{FX}}$

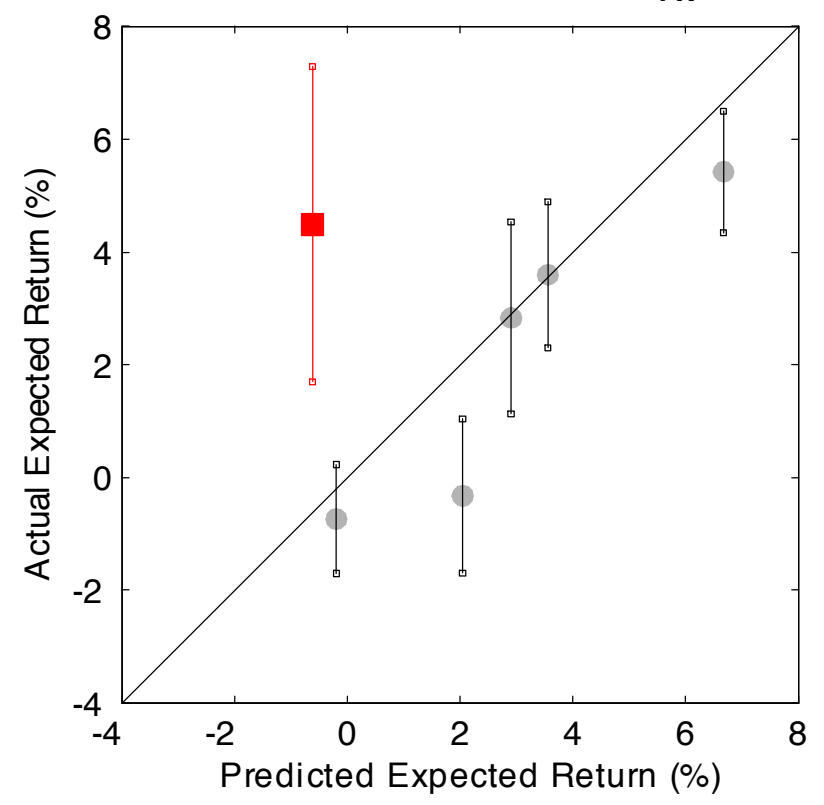

(b) Model 2: DOL and VOL

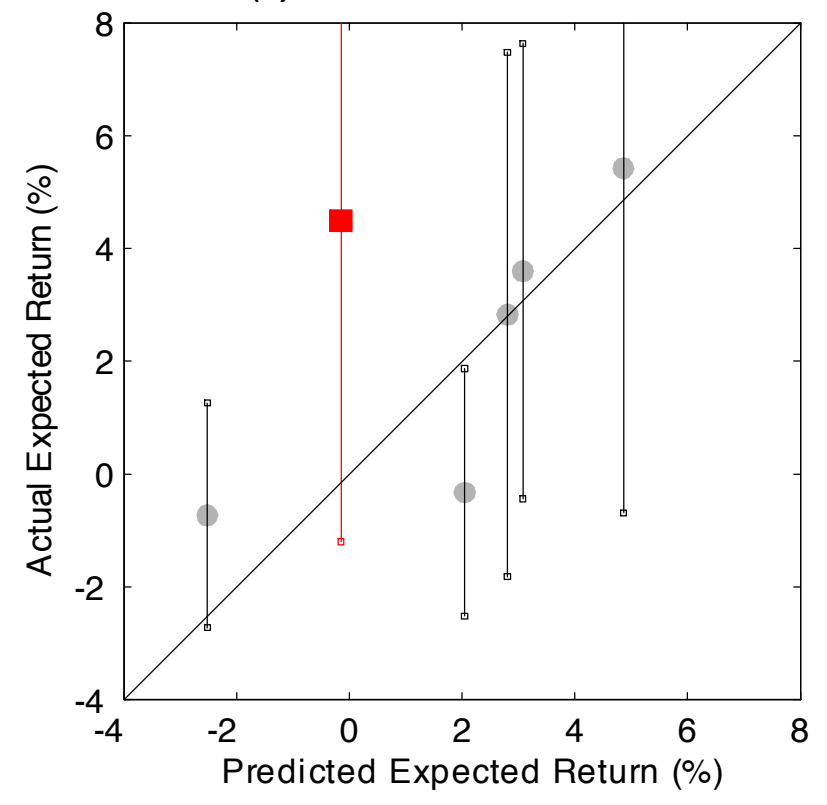

Note: For each portfolio, the graph plots the average annualized payoffs of each portfolio, $\bar{x}$ 
(on the $\mathrm{y}$-axis), against the model-predicted mean return, $\hat{z}$ (on the $\mathrm{x}$-axis). The gray dots correspond to the S1-S5 currency portfolios sorted on the basis of the forward discount. The red square represents the momentum portfolio. The vertical lines extending above and below each point are two-standard error bands for each portfolio's pricing error. When these lines do not cross the 45 degree line, the pricing error is statistically significant at the 5 percent level. 
Table 1: Annualized excess returns of investment strategies (Feb. 1976-Dec. 2010)

\begin{tabular}{lccccccc}
\hline & $\begin{array}{c}\text { Mean } \\
(\%)\end{array}$ & $\begin{array}{c}\text { SD } \\
(\%)\end{array}$ & $\begin{array}{c}\text { Sharpe } \\
\text { Ratio }\end{array}$ & Skewness & \multicolumn{2}{c}{$\begin{array}{c}\text { Excess } \\
\text { Kurtosis }\end{array}$} & \multicolumn{2}{c}{ Correlation with } \\
\hline
\end{tabular}

${ }^{a}$ The mean excess returns of the currency portfolios are not equal to the average mean excess returns of the respective individual-currency trades because the sample period varies by currency.

${ }^{\mathrm{b}}$ Heteroskedasticity-consistent GMM standard errors are in parentheses.

${ }^{\mathrm{c}}$ The carry trade (momentum) portfolio is formed as the average of up to 20 individual currency carry (momentum) trades against the USD.

${ }^{\mathrm{d}}$ The 50-50 strategy is an equally-weighted average of the carry and momentum portfolios.

${ }^{\mathrm{e}}$ The U.S. stock market return is the value-weighted excess return on all U.S. stocks. 
Table 2: Factor betas of the currency portfolios (1976-2010)

\begin{tabular}{|c|c|c|c|c|c|c|c|c|}
\hline \multirow[b]{2}{*}{ Factor Model } & \multicolumn{4}{|c|}{ Carry Trade } & \multicolumn{4}{|c|}{ Momentum } \\
\hline & & $\operatorname{Beta}(s)^{a}$ & & $R^{2}$ & & $\operatorname{Beta}(s)^{a}$ & & $R^{2}$ \\
\hline $\mathrm{CAPM}^{\mathrm{b}}$ & $\begin{array}{c}0.029 \\
(0.017)\end{array}$ & & & 0.01 & $\begin{array}{l}-0.042 \\
(0.036)\end{array}$ & & & 0.01 \\
\hline Fama-French $^{\mathrm{c}}$ & $\begin{array}{c}0.045^{*} \\
(0.018)\end{array}$ & $\begin{array}{l}-0.034 \\
(0.030)\end{array}$ & $\begin{array}{c}0.042 \\
(0.029)\end{array}$ & 0.02 & $\begin{array}{l}-0.037 \\
(0.040)\end{array}$ & $\begin{array}{l}-0.030 \\
(0.036)\end{array}$ & $\begin{array}{l}-0.001 \\
(0.047)\end{array}$ & 0.01 \\
\hline Quadratic CAPM $^{\mathrm{d}}$ & $\begin{array}{c}0.033 \\
(0.019)\end{array}$ & $\begin{array}{c}0.286 \\
(0.343)\end{array}$ & & 0.01 & $\begin{array}{l}-0.027 \\
(0.028)\end{array}$ & $\begin{array}{c}1.202 \\
(1.368)\end{array}$ & & 0.02 \\
\hline CAPM-Volatility $^{\mathrm{e}}$ & $\begin{array}{l}-0.004 \\
(0.026)\end{array}$ & $\begin{array}{l}-0.010 \\
(0.231)\end{array}$ & $\begin{array}{c}2.093 \\
(1.627)\end{array}$ & 0.02 & $\begin{array}{l}-0.012 \\
(0.066)\end{array}$ & $\begin{array}{c}0.001 \\
(0.232)\end{array}$ & $\begin{array}{l}-1.885 \\
(5.212)\end{array}$ & 0.01 \\
\hline C-CAPM ${ }^{\mathrm{f}}$ & $\begin{array}{c}0.006 \\
(0.733)\end{array}$ & & & 0.00 & $\begin{array}{l}-0.583 \\
(0.840)\end{array}$ & & & 0.00 \\
\hline Extended C-CAPM ${ }^{\mathrm{g}}$ & $\begin{array}{l}-0.314 \\
(0.824)\end{array}$ & $\begin{array}{c}0.671 \\
(0.572)\end{array}$ & $\begin{array}{c}0.013 \\
(0.031)\end{array}$ & 0.01 & $\begin{array}{l}-0.176 \\
(0.765)\end{array}$ & $\begin{array}{l}-0.712 \\
(0.718)\end{array}$ & $\begin{array}{l}-0.070 \\
(0.047)\end{array}$ & 0.04 \\
\hline
\end{tabular}

${ }^{a}$ The table reports estimates of the slope coefficients and the $R^{2}$ in a regression of the portfolio payoffs on a constant and the indicated risk factors. Heteroskedasticity consistent standard errors are in parentheses. Slope coefficients that are statistically significant at the 5 percent level are indicated by an asterisk( $\left(^{*}\right)$. Payoffs are monthly nominal excess returns, and the sample period is Mar. 1976-Dec. 2010 unless otherwise indicated.

${ }^{\mathrm{b}}$ The CAPM model uses a single factor, the excess return on the value-weighted US stock market (Mkt-Rf).

'The Fama-French model uses Mkt-Rf as well as Fama and French's SMB and HML factors.

${ }^{\mathrm{d}}$ The Quadratic CAPM uses Mkt-Rf and $1 / 2(\mathrm{Mkt}-\mathrm{Rf})^{2}$ as factors. 
${ }^{\mathrm{e}}$ The CAPM-Volatility model uses Mkt-Rf and stock volatility (the standard deviation of daily excess returns, measured monthly), and their interaction as factors.

${ }^{\mathrm{f}}$ The C-CAPM model uses the log growth rate of real consumption of nondurables and services, and is estimated with quarterly real excess returns, 1976Q2-2010Q1.

${ }^{\mathrm{g}}$ The extended C-CAPM model uses the C-CAPM factor, the log growth rate of the service flow of durables (assumed to be proportional to the real stock of consumer durables), and the market return (Mkt), as factors. 
Table 3: GMM estimates of linear factor models* (Mar. 1976-Dec. 2010)

\begin{tabular}{|c|c|c|c|c|c|c|}
\hline \multirow[b]{2}{*}{ Factor Model } & \multirow[t]{2}{*}{$b^{\mathrm{a}}$} & \multirow[t]{2}{*}{$\lambda^{b}$} & \multirow[t]{2}{*}{$R^{2 \mathrm{c}}$} & \multirow[t]{2}{*}{$J^{d}$} & \multicolumn{2}{|c|}{ Pricing Errors $(\%)^{\mathrm{e}}$} \\
\hline & & & & & Carry & Momentum \\
\hline CAPM & $\begin{array}{l}2.4^{*} \\
(1.2)\end{array}$ & $\begin{array}{l}0.49^{*} \\
(0.22)\end{array}$ & -1.50 & $\begin{array}{r}106.00 \\
(0.00)\end{array}$ & $\begin{array}{c}4.4^{*} \\
(0.9)\end{array}$ & $\begin{array}{c}4.7^{*} \\
(1.3)\end{array}$ \\
\hline $\begin{array}{l}\text { Fama-French } \\
\text { Mkt-Rf }\end{array}$ & $\begin{array}{l}3.5^{*} \\
(1.4)\end{array}$ & $\begin{array}{l}0.53^{*} \\
(0.23)\end{array}$ & 0.38 & $\begin{array}{l}92.73 \\
(0.00)\end{array}$ & $\begin{array}{c}4.2^{*} \\
(0.9)\end{array}$ & $\begin{array}{c}4.8^{*} \\
(1.4)\end{array}$ \\
\hline SMB & $\begin{array}{c}3.2 \\
(1.8)\end{array}$ & $\begin{array}{l}0.24 \\
(0.15)\end{array}$ & & & & \\
\hline HML & $\begin{array}{c}6.4^{*} \\
(1.9)\end{array}$ & $\begin{array}{l}0.34^{*} \\
(0.17)\end{array}$ & & & & \\
\hline $\begin{array}{l}\text { Quadratic CAPM } \\
\text { Mkt-Rf }\end{array}$ & $\begin{array}{c}0.3 \\
(1.5)\end{array}$ & $\begin{array}{l}0.25 \\
(0.23)\end{array}$ & -3.72 & $\begin{array}{l}99.38 \\
(0.00)\end{array}$ & $\begin{array}{l}4.6^{*} \\
(0.9)\end{array}$ & $\begin{array}{l}5.0^{*} \\
(1.4)\end{array}$ \\
\hline $1 / 2(\mathrm{Mkt}-\mathrm{Rf})^{2}$ & $\begin{array}{l}-70.8 \\
(74.7)\end{array}$ & $\begin{array}{l}-0.03 \\
(0.03)\end{array}$ & & & & \\
\hline $\begin{array}{l}\text { CAPM-Volatility } \\
\text { Mkt-Rf }\end{array}$ & $\begin{array}{l}-5.7 \\
(4.9)\end{array}$ & $\begin{array}{c}0.04 \\
(0.24)\end{array}$ & -7.37 & $\begin{array}{l}90.80 \\
(0.00)\end{array}$ & $\begin{array}{l}4.2^{*} \\
(0.9)\end{array}$ & $\begin{array}{l}4.8^{*} \\
(1.7)\end{array}$ \\
\hline Stock volatility & $\begin{array}{l}-16.7 \\
(42.4)\end{array}$ & $\begin{array}{l}-0.09 \\
(0.09)\end{array}$ & & & & \\
\hline Mkt-Rf $\times$ Stock vol & $\begin{array}{c}325.5 \\
(406.7)\end{array}$ & $\begin{array}{c}0.01 \\
(0.01)\end{array}$ & & & & \\
\hline
\end{tabular}

*Test assets are the Fama-French 25 portfolios, and the equally-weighted carry trade and currency momentum portfolios. See Table 2 for the definitions of risk factors.

Heteroskedasticity-consistent standard errors are in parentheses, except as noted. An asterisk $\left(^{*}\right)$ indicates statistical significance at the 5 percent level.

${ }^{\mathrm{a}} b$ is the parameter vector in the SDF, $m=1-(f-\mu)^{\prime} b$. 
${ }^{\mathrm{b}} \lambda$ is the vector of risk premia associated with the factors.

${ }^{\mathrm{c}} R^{2}$ is a measure of fit between the sample average and model-predicted mean returns.

${ }^{\mathrm{d}} J$ is the test statistic for the overidentifying restrictions are also reported. P-values are reported in parentheses.

${ }^{\mathrm{e}}$ Annualized \%. 
Table 4: GMM estimates of linear factor models* (1976Q2-2010Q1)

\begin{tabular}{|c|c|c|c|c|c|c|}
\hline \multirow[b]{2}{*}{ Factor Model } & \multirow[t]{2}{*}{$b^{\mathrm{a}}$} & \multirow[t]{2}{*}{$\lambda^{\mathrm{b}}$} & \multirow[t]{2}{*}{$R^{2 \mathrm{c}}$} & \multirow[t]{2}{*}{$J^{d}$} & \multicolumn{2}{|c|}{ Pricing Errors $(\%)^{\mathrm{e}}$} \\
\hline & & & & & Carry & Momentum \\
\hline C-CAPM & $\begin{array}{l}-15.2 \\
(43.7)\end{array}$ & $\begin{array}{l}-0.03 \\
(0.08)\end{array}$ & -10.00 & $\begin{array}{l}72.02 \\
(0.00)\end{array}$ & $\begin{array}{c}4.7^{*} \\
(1.0)\end{array}$ & $\begin{array}{c}4.6^{*} \\
(1.3)\end{array}$ \\
\hline $\begin{array}{r}\text { Extended C-CAPM } \\
\Delta \ln \text { (consumption) }\end{array}$ & $\begin{array}{l}-17.0 \\
(50.4)\end{array}$ & $\begin{array}{l}-0.03 \\
(0.08)\end{array}$ & -0.70 & $\begin{array}{l}61.77 \\
(0.00)\end{array}$ & $\begin{array}{c}4.7^{*} \\
(1.0)\end{array}$ & $\begin{array}{c}5.3^{*} \\
(1.4)\end{array}$ \\
\hline$\Delta \ln$ (durables) & $\begin{array}{l}-15.5 \\
(36.1)\end{array}$ & $\begin{array}{l}-0.06 \\
(0.08)\end{array}$ & & & & \\
\hline Mkt & $\begin{array}{l}2.8^{*} \\
(1.2)\end{array}$ & $\begin{array}{l}1.90^{*} \\
(0.72)\end{array}$ & & & & \\
\hline
\end{tabular}

*Test assets are the Fama-French 25 portfolios, and the equally-weighted carry trade and currency momentum portfolios. See Table 2 for the definitions of risk factors.

Heteroskedasticity-consistent standard errors are in parentheses, except as noted. An asterisk $\left({ }^{*}\right)$ indicates statistical significance at the 5 percent level.

${ }^{\mathrm{a}} b$ is the parameter vector in the SDF, $m=1-(f-\mu)^{\prime} b$.

${ }^{\mathrm{b}} \lambda$ is the vector of risk premia associated with the factors.

${ }^{\mathrm{c}} R^{2}$ is a measure of fit between the sample average and model-predicted mean returns.

${ }^{\mathrm{d}} J$ is the test statistic for the overidentifying restrictions are also reported. P-values are reported in parentheses.

${ }^{\mathrm{e}}$ Annualized \%. 
Table 5: Factor betas of the sorted, carry, and momentum portfolios

\begin{tabular}{|c|c|c|c|c|c|c|c|}
\hline \multirow[b]{3}{*}{ Portfolio $^{b}$} & \multirow{3}{*}{$\begin{array}{c}\text { Mean } \\
\text { Return } \\
(\%)\end{array}$} & \multicolumn{6}{|c|}{ Betas $^{\mathrm{a}}$} \\
\hline & & \multicolumn{3}{|c|}{ Model 1} & \multicolumn{3}{|c|}{ Model 2} \\
\hline & & $\mathrm{DOL}^{\mathrm{c}}$ & $\mathrm{HML}_{\mathrm{FX}}{ }^{\mathrm{d}}$ & $R^{2}$ & $\mathrm{DOL}^{\mathrm{c}}$ & $\mathrm{VOL}^{\mathrm{e}}$ & $R^{2}$ \\
\hline $\mathrm{S} 1$ & $\begin{array}{l}-0.7 \\
(1.9)\end{array}$ & $\begin{array}{c}1.03^{*} \\
(0.02)\end{array}$ & $\begin{array}{l}-0.48^{*} \\
(0.02)\end{array}$ & 0.93 & $\begin{array}{c}1.01^{*} \\
(0.04)\end{array}$ & $\begin{array}{c}2.1^{*} \\
(0.5)\end{array}$ & 0.75 \\
\hline S2 & $\begin{array}{l}-0.3 \\
(1.7)\end{array}$ & $\begin{array}{c}0.95^{*} \\
(0.03)\end{array}$ & $\begin{array}{l}-0.12^{*} \\
(0.02)\end{array}$ & 0.85 & $\begin{array}{c}0.94^{*} \\
(0.03)\end{array}$ & $\begin{array}{l}-0.1 \\
(0.5)\end{array}$ & 0.83 \\
\hline S3 & $\begin{array}{c}2.8 \\
(1.8)\end{array}$ & $\begin{array}{c}0.98^{*} \\
(0.03)\end{array}$ & $\begin{array}{l}-0.00 \\
(0.03)\end{array}$ & 0.83 & $\begin{array}{c}0.97^{*} \\
(0.03)\end{array}$ & $\begin{array}{l}-0.4 \\
(0.3)\end{array}$ & 0.83 \\
\hline S4 & $\begin{array}{c}3.6 \\
(1.8)\end{array}$ & $\begin{array}{c}1.02^{*} \\
(0.03)\end{array}$ & $\begin{array}{c}0.08^{*} \\
(0.02)\end{array}$ & 0.86 & $\begin{array}{c}1.02^{*} \\
(0.03)\end{array}$ & $\begin{array}{l}-0.5 \\
(0.3)\end{array}$ & 0.86 \\
\hline S5 & $\begin{array}{c}5.3 \\
(2.1)\end{array}$ & $\begin{array}{c}1.03^{*} \\
(0.02)\end{array}$ & $\begin{array}{c}0.52^{*} \\
(0.02)\end{array}$ & 0.94 & $\begin{array}{c}1.06^{*} \\
(0.04)\end{array}$ & $\begin{array}{l}-1.3^{*} \\
(0.5)\end{array}$ & 0.73 \\
\hline Carry & $\begin{array}{c}4.6 \\
(0.9)\end{array}$ & $\begin{array}{c}0.20^{*} \\
(0.04)\end{array}$ & $\begin{array}{c}0.26^{*} \\
(0.03)\end{array}$ & 0.38 & $\begin{array}{c}0.21^{*} \\
(0.05)\end{array}$ & $\begin{array}{l}-0.8^{*} \\
(0.4)\end{array}$ & 0.15 \\
\hline Momentum & $\begin{array}{c}4.5 \\
(1.2)\end{array}$ & $\begin{array}{c}0.03 \\
(0.08)\end{array}$ & $\begin{array}{l}-0.10 \\
(0.06)\end{array}$ & 0.02 & $\begin{array}{c}0.02 \\
(0.08)\end{array}$ & $\begin{array}{c}0.1 \\
(1.0)\end{array}$ & 0.00 \\
\hline
\end{tabular}

${ }^{\text {a }}$ The table reports estimates of the slope coefficients and the $R^{2}$ in a regression of the portfolio payoffs on a constant and the indicated risk factors. Heteroskedasticity consistent standard errors are in parentheses. Slope coefficients that are statistically significant at the 5 percent level are indicated by an asterisk $\left(^{*}\right)$. Payoffs are monthly nominal excess returns, and the sample period is Mar. 1976-Dec. 2010.

${ }^{b}$ The portfolios are five portfolios of long positions in foreign currency sorted in increasing order by the forward discount (S1-S5), the carry trade portfolio and the momentum portfolio.

${ }^{\mathrm{c}}$ The DOL factor is the average excess return to portfolios S1-S5. 
${ }^{\mathrm{d}}$ The HML $\mathrm{HX}_{\mathrm{F}}$ factor is the excess return to being long portfolio S5 and short portfolio S1. ${ }^{\mathrm{e}}$ The VOL factor is a measure of realized global currency volatility. 
Table 6: GMM estimates of currency-factor-based models* (Mar. 1976-Dec. 2010)

\begin{tabular}{|c|c|c|c|c|c|c|c|c|c|c|}
\hline \multirow[b]{2}{*}{ Factor Model } & \multirow[t]{2}{*}{$b^{\mathrm{a}}$} & \multirow[t]{2}{*}{$\lambda^{b}$} & \multirow[t]{2}{*}{$R^{2 \mathrm{c}}$} & \multirow[t]{2}{*}{$J^{d}$} & \multicolumn{6}{|c|}{$\begin{array}{l}\text { Pricing Errors (\%) } \\
\end{array}$} \\
\hline & & & & & S1 & S2 & S3 & S4 & S5 & Mom. ${ }^{f}$ \\
\hline \multicolumn{11}{|l|}{ Model 1} \\
\hline DOL & $\begin{array}{c}3.7 \\
(2.2)\end{array}$ & $\begin{array}{c}0.25 \\
(0.12)\end{array}$ & -0.04 & $\begin{array}{l}18.90 \\
(0.00)\end{array}$ & $\begin{array}{l}-0.5 \\
(0.5)\end{array}$ & $\begin{array}{l}-2.4 \\
(0.7)\end{array}$ & $\begin{array}{l}-0.1 \\
(0.9)\end{array}$ & $\begin{array}{c}0.0 \\
(0.7)\end{array}$ & $\begin{array}{l}-1.3 \\
(0.5)\end{array}$ & $\begin{array}{c}5.1 \\
(1.4)\end{array}$ \\
\hline $\mathrm{HML}_{\mathrm{FX}}$ & $\begin{array}{c}7.4 \\
(2.1)\end{array}$ & $\begin{array}{c}0.57 \\
(0.13)\end{array}$ & & & & & & & & \\
\hline \multicolumn{11}{|l|}{ Model 2} \\
\hline DOL & $\begin{array}{c}0.3 \\
(3.4)\end{array}$ & $\begin{array}{c}0.17 \\
(0.16)\end{array}$ & 0.04 & $\begin{array}{c}6.51 \\
(0.16)\end{array}$ & $\begin{array}{c}1.8 \\
(1.0)\end{array}$ & $\begin{array}{l}-2.4 \\
(1.1)\end{array}$ & $\begin{array}{c}0.0 \\
(2.4)\end{array}$ & $\begin{array}{c}0.5 \\
(2.1)\end{array}$ & $\begin{array}{c}0.6 \\
(3.1)\end{array}$ & $\begin{array}{c}4.6 \\
(2.9)\end{array}$ \\
\hline VOL & $\begin{array}{l}-3.9 \\
(1.6)\end{array}$ & $\begin{array}{r}-17.93 \\
(6.73)\end{array}$ & & & & & & & & \\
\hline
\end{tabular}

*Test assets are five portfolios of long positions in foreign currency sorted in increasing order by the forward discount (S1-S5), and the momentum portfolio. See Table 5 for the definitions of risk factors. Heteroskedasticity-consistent standard errors are in parentheses, except as noted. An asterisk $\left(^{*}\right)$ indicates statistical significance at the 5 percent level.

${ }^{\text {a }} b$ is the parameter vector in the SDF, $m=1-(f-\mu)^{\prime} b$.

${ }^{\mathrm{b}} \lambda$ is the vector of risk premia associated with the factors.

${ }^{\mathrm{c}} R^{2}$ is a measure of fit between the sample average and model-predicted mean returns. ${ }^{\mathrm{d}} J$ is the test statistic for the overidentifying restrictions are also reported. P-values are reported in parentheses.

\footnotetext{
${ }^{\mathrm{e}}$ Annualized \%

${ }^{\mathrm{f}}$ Momentum
} 